O governo da Saúde Mental em Portugal e no Brasil

\title{
Racionalidades leigas e governação da Saúde Mental em Portugal
}

Fátima Alves(a)

Karine Wlasenko Nicolau ${ }^{(b)}$

Alves F, Nicolau KW. Lay rationalities and Mental Health governance in Portugal. Interface (Botucatu). 2017; 21(63):799-810.

The paper reaffirms the importance of lay rationalities that are produced in the Mental Health field as valid expressions of knowledge, with special attention to the ethical aspects related to the social use of knowledge. The paper argues that those rationalities should serve to create innovative strategies to effectively address the needs of people and act as a counterweight to the hegemonic logic. The context of governance of Mental Health in Portugal and the structural characteristics of the Portuguese society are reflected in the services as they are effectively implemented and in the users' perception about their condition. The appreciation of lay rationalities in a context ruled by biomedical and technical aspects enables to reaffirm diversity as a human condition. Therefore it is a basic tenet for an approach to complex and plural realities such as mental health, incorporating the cultural dimension to the actions developed.

Keywords: Lay rationalities. Portuguese mental health. Deinstitutionalization.
O artigo reafirma a importância das racionalidades leigas produzidas em Saúde Mental como expressões válidas de saber, com especial atenção aos aspectos éticos relacionados aos usos sociais dos conhecimentos gerados. Defende-se a ideia de que devem servir à criação de estratégias inovadoras que respondam efetivamente às necessidades das pessoas e como contrapoderes às lógicas hegemônicas. $\mathrm{O}$ contexto da governação da Saúde Mental em Portugal e as características estruturais da sociedade portuguesa refletem-se nos serviços efetivamente implementados e na percepção dos usuários a respeito da sua condição. A valorização das racionalidades leigas em um cenário hegemonicamente tecnicista e biomédico possibilita reafirmar a diversidade como condição humana. Nessa direção, insere-se como fundamento para a abordagem em realidades complexas e plurais como a Saúde Mental, incorporando a dimensão cultural às ações desenvolvidas.

Palavras-chave: Racionalidades leigas. Saúde mental portuguesa. Desinstitucionalização.

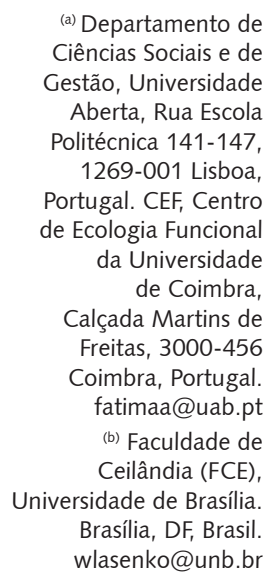

(a) Departamento de Ciências Sociais e de Gestão, Universidade Aberta, Rua Escola Politécnica 141-147, 1269-001 Lisboa, Portugal. CEF, Centro de Ecologia Funcional da Universidade de Coimbra, Calçada Martins de Freitas, 3000-456 Coimbra, Portugal. fatimaa@uab.pt (b) Faculdade de Ceilândia (FCE), Universidade de Brasília. Brasília, DF, Brasil. wlasenko@unb.br 


\section{Introdução}

\section{As potencialidades heurísticas das racionalidades leigas}

A expressão "racionalidades leigas em Saúde Mental" refere-se ao saber leigo sobre saúde e doença mental e se relaciona intimamente com o estudo dos conhecimentos e lógicas de ação e com os significados que as pessoas atribuem à doença mental, na tentativa de lhe conferir sentidos e de compreender suas causas, interpretando continuamente e de forma dinâmica a experiência vivida de acordo com os sentidos de seu grupo ${ }^{1}$, sendo por isso contingentes, subjetivas, processuais e dinâmicas².

O estudo das racionalidades leigas permite a aproximação da complexidade intrínseca às relações sociais estabelecidas em Saúde Mental, sempre muito aquém e além da normatividade nosográfica e diagnóstica que orienta o saber psiquiátrico.

O conceito ampliado de racionalidades leigas ${ }^{1-6}$ pode ser localizado em publicações anteriores, pois aqui serão abordados os aspectos que se desdobram em relação ao conceito, ratificando sua centralidade para a formulação de políticas públicas e evidenciando potencialidades e desafios atuais no contexto da governação da Saúde Mental portuguesa.

Em sua composição, o termo "racionalidades" remete à raiz rationalitas, termo do latim que remete à capacidade de raciocinar e argumentar? ${ }^{7}$. Na acepção adotada e de modo simplificado, traduz-se diferentes formas de organizar ideias, conhecimentos, pensamentos e ações relativos à Saúde Mental por meio de um sentido lógico próprio, que pode incluir a linguagem psiquiátrica, embora com significados diferentes.

Em outras palavras, as racionalidades leigas combinam de diversas formas as múltiplas dimensões e os conhecimentos plurais que integram, evidenciando as interdependências subjacentes às explicações e soluções que conduzem à busca por uma vida melhor.

Assim, o conceito procura responder ao desafio da ação (revelando modos de fazer, respostas, estratégias e recursos) e ao da significação (dos sentidos que essa ação assume nos contextos nos quais é requerida). As racionalidades encerram em si, desse modo, uma pluralidade de possibilidades que em cada contexto específico podem ser mobilizadas².

Etimologicamente, o termo "leigo" deriva mais recentemente do latim laicus, que significa o que não pertence ou o que não está ligado a nenhuma religião ${ }^{8}$. No entanto, sua raiz pode ser localizada no grego laikós, "do povo", tanto em oposição aos líderes quanto em relação aos diversos grupos populares em si ${ }^{9}$. Como qualificador de uma determinada expressão de conhecimento em Saúde, poderia ser identificado como aquele que não está vinculado diretamente à expertise profissional, mas que configura um dos campos do saber humano, baseado nas vivências cotidianas e no senso comum compartilhado. Refere-se a construções coletivas que se expressam em arranjos singulares.

O campo de estudo das racionalidades leigas em Saúde Mental reconhece como condição humana a diversidade de crenças e de representações relativas à existência. Não pretende reforçar dicotomias ou estabelecer polarizações com o saber biomédico, mas conferir visibilidade à complexa trama que se desenvolve no estar com o outro e suas diferenças.

Parte-se da premissa de que "as racionalidades leigas orientam as trajetórias sociais de saúde e de doença"1 (p. 248). Convém destacar que não se trata de um conhecimento estático, mas afeito à reflexividade ${ }^{10}$ e à reconstrução na interação, nas quais os discursos são transformados de acordo com contextos específicos para a resolução de problemas quotidianos identificáveis e concretos.

Questões que envolvem a diversidade humana certamente não se limitam ao campo da Saúde Mental. Reconhecer os sujeitos como efetivamente capazes de interferir e participar dos processos que afetam suas vidas: eis a direção que o estudo das racionalidades leigas nos aponta. No entanto, há a necessidade de identificar o contexto em que tais racionalidades se expressam, do qual recebem influências e no qual são (re)elaboradas, modificando-se em meio às relações sócio-históricas.

$\mathrm{O}$ artigo identifica o campo de estudos das chamadas racionalidades leigas como acesso privilegiado ao saber mobilizado no quotidiano que organiza e direciona interpretações, concepções e ações na construção de trajetórias sociais de saúde e de doença mental. 
Para tanto, fundamenta-se na reflexão resultante de investigações sociológicas desenvolvidas a partir do contexto português nas últimas décadas, no intuito de situá-las como contributos indispensáveis à efetivação das transformações no atendimento em Saúde Mental, em especial no que se refere à Reforma Psiquiátrica, iniciada no país há mais de cinco décadas.

\section{Racionalidades leigas e desafios à governação da Saúde Mental}

O desafio de escutar as racionalidades leigas em torno da Saúde Mental, dando expressão às vivências e à voz dos leigos, às suas concepções e soluções, às múltiplas estratégias de cuidado e às lógicas de produção desse cuidado relaciona-se à criação de espaços de autonomia, diálogo e influência na necessária reconstrução dos sistemas de Saúde Mental oficiais².

Contudo, afirmar a importância das racionalidades leigas no contexto da reconfiguração dos sistemas de Saúde Mental exige que se compreendam os sistemas mais amplos nos quais os modos de produção social da saúde se constroem.

O estudo das racionalidades leigas reflete mediações relativas às configurações socioeconômicas dos países e contextos locais nos quais se expressam. Aliadas às características estruturais das diversas sociedades, ratifica-se uma preocupação ética que se dirige tanto aos conhecimentos incorporados por essas racionalidades em si quanto ao contexto de governação da Saúde Mental. Tal questão se refere:

[...] aos usos sociais do conhecimento que as racionalidades leigas podem proporcionar caso não se constituam como contrapoderes/saberes às lógicas hegemónicas que imperam neste campo (como por exemplo da biomedicina - que inclui organizações e profissionais; da administração e gestão), na criação de respostas inovadoras que respondam efetivamente às necessidades das pessoas e valorizem a importância das dimensões sociais e culturais da ação e que com elas se articulem. Ou seja, conhecer não para dominar nem para domesticar, catequizar ou colonizar com mais facilidade, mas para articular e criar sistemas mais humanos, favorecedores de reais cidadanias participativas, modelos eventualmente alternativos aos sistemas em vigor que continuam a não resolver o problema da equidade no acesso à saúde (seja pela falta ou desmantelamento de respostas, seja pela exigência de taxas e pagamentos cada vez mais elevados, sobretudo em grupos de risco ou em situação de vulnerabilidade social ou ainda pela diminuição ou corte nas comparticipações de medicamentos ou outros meios de diagnóstico e terapêutica, bem como do congelamento das reformas em curso². (p. 113-4)

De acordo com Silva ${ }^{11}$ (p. 175), as racionalidades leigas referem-se a uma lógica pragmática de conciliação com os contextos em questão. Assim, a contradição que expressam é apenas aparente, pois, no "pensamento leigo, ter saúde não é apenas não ter sintomas de doença, mas é, em grande medida, ser capaz de resolver o mal-estar provocado pelos sintomas sem recorrer à medicina", o que se impõe como desafio à formulação de políticas públicas, nas quais a acessibilidade apresenta-se como princípio fundamental.

Sob outro aspecto, a idealização da loucura, seja de forma positiva ou negativa, parece dificultar o contato com as reais necessidades dessas pessoas que de facto parecem oscilar entre a proteção assistida e vivências mais ricas e significativas no âmbito social, psicológico, simbólico, corporal e espiritual.

Na seara do atendimento e das chamadas "boas práticas", a procura por evidências científicas em Saúde Mental pode conduzir, contraditoriamente, aos vazios resolutivos tão bem conhecidos e

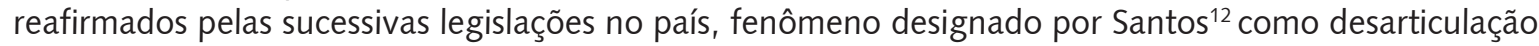
interna.

O conhecimento que se produz no âmbito da avaliação técnica e na busca por evidências - no sentido estrito de se obter orientações padronizadas para a tomada de decisão, muitas vezes para a racionalização de custos sob a égide da efetividade, - ao não contemplar as concepções e percepções dos agentes, ignora fatores decisivos para o reconhecimento e para a efetividade dos serviços implantados. Para Carapinheiro e Correia ${ }^{13}$, constituem uma fonte de custos na saúde que não se vê 
e que, adensados em registros relacionais e culturais, não se deixam capturar por artefatos técnicoestatísticos.

No âmbito da integração comunitária, por exemplo, metodologias de treinamento social inclusivo, como a Boston University Approach to Psychiatric Rehabilitation (BPR ${ }^{14}$, que prevê o incremento da participação social em atividades laborais comunitárias com base em metas mais acessíveis e menos competitivas, destacam-se por valorizarem o autocuidado e despontam como alternativas viáveis, de baixo custo, se comparadas aos tratamentos usuais. No entanto, seu incentivo e fortalecimento não deve ignorar que o efetivo reconhecimento da diversidade deve extrapolar os muros do establishment, pois isso reflete a disposição para avançar sem estreitamentos e limitações identificados como potenciais fatores para o adoecimento psíquico ${ }^{1}$.

Sob esse aspecto, a inclusão das racionalidades leigas no processo de pactuação desponta como fator crucial de preservação identitária, que Alves ${ }^{1}$ localiza como aspecto central no processo saúdedoença mental. Trata-se de um importante recurso a fim de não subsumir à "identidade deteriorada", nos termos de Goffman ${ }^{15}$.

De um ponto de vista sociológico e também psicológico, a identificação da vulnerabilidade em que se encontram aqueles que convivem com transtornos mentais deve caminhar pari passu com o direito que tais pessoas têm de vivenciar potencialidades no decurso de sua vida. Contudo, trata-se de um equacionamento que requer mais do que técnicas e saberes especializados, não sendo possível estabelecer a priori o que será recebido e identificado como efetiva assistência em Saúde Mental e o que se apresentará como cerceamento de liberdades e de autonomia ${ }^{16}$.

O estudo das racionalidades leigas, em suas expressões plurais, permite a aproximação com arranjos singulares, carregados e constituídos de vivências coletivas, de rede de relações que transfiguram crenças e verdades relativas ao longo do caminho, como diria Foucault ${ }^{17}$, de modo mais ou menos intenso e mais ou menos duradouro.

As respostas oferecidas pelos serviços de Saúde Mental, quando organizadas para atender a pressupostos de políticas formuladas sem a participação das comunidades e de seus saberes e contextos locais, diminuem consideravelmente sua legitimidade, como atestam, por exemplo, os estudos de Henderson e Fuller ${ }^{18}$. Segundo os pesquisadores australianos, as políticas de saúde criam um quadro discursivo para a compreensão das questões sociais por meio da produção dos problemas de determinado modo, excluindo representações alternativas da questão (principalmente em relação à população beneficiária) e limitando as possibilidades de intervenção. O processo investigativo empreendido pelos autores sobre a política de saúde australiana para pessoas com transtornos mentais revelou que a mera disponibilização de cuidados integrados para serem "escolhidos" pelos "consumidores" considerados responsáveis por sua saúde demonstrou pouco impacto sobre o acesso aos serviços. Os usuários do sistema de saúde não tiveram maior e melhor acesso aos serviços porque estes estavam disponibilizados formalmente. Algo escapou na formulação e no planejamento da proposta, comprometendo o resultado esperado.

Nessa direção, pode-se afirmar que o incremento de leis, decretos, portarias e afins não garante mudanças no atendimento em Saúde Mental, pois a complexidade desse processo não se encerra nos discursos formais e deve incluir as racionalidades leigas, a fim de que tenha vida e movimento.

Para Alves ${ }^{19}$, "as racionalidades leigas manifestam resistência à medicalização da vida e à psiquiatrização das sociedades, reivindicando a competência de gestão dos 'sofrimentos' do quotidiano" (p. 235), cuja representação é de normalidade, na medida em que são considerados integrantes da vida. O estudo descrito a seguir ratifica essa afirmativa.

\section{Investigação em um serviço comunitário}

Em investigação recente conduzida em um serviço comunitário de referência na cidade do Porto ${ }^{20}$, ao norte de Portugal, as análises resultantes sugerem intrigantes percepções dos usuários sobre o processo de recovery, norteador das ações desenvolvidas na unidade, reconhecida no país como Pessoa Coletiva de Utilidade Pública e que atende pessoas que convivem com transtornos mentais do espectro esquizofrênico. 
A ideia de recovery relaciona-se, segundo revisão sistemática do conceito empreendida por Baccari, Onocko-Campos e Stefanello²1, a uma condição que prioriza "o quão participativa pode ser a vida de um indivíduo na comunidade não obstante a doença" (p. 134) e que se refere, de acordo com Teixeira22, "a um processo profundamente pessoal e único de mudança de atitudes, valores, sentimentos, objetivos, competências e/ou papéis" (p. 19).

Após observação participante das atividades desenvolvidas e de entrevistas semiestruturadas com usuários, os dados produzidos indicam que se confere à autoridade e às rotinas planejadas e preestabelecidas um caráter normalizador da vida que é valorizado como organizador e facilitador da inserção social. Paralelamente, verificou-se que os discursos dos utentes relativos à desinstitucionalização não se servem da luta contra as estruturas manicomiais em si, mas do maior encurtamento possível em caso de internação, considerada necessária e muitas vezes inevitável.

No processo investigativo, verificou-se que as racionalidades leigas expressaram subjetividades moldadas em um cenário moderno e individualizante, voltado para o autocuidado e para a responsabilização por si. A despolitização dos usuários em relação a questões coletivas reafirmou-se, por um lado; e, por outro, os discursos revelaram o ânimo para a construção de um novo "modo de andar a vida", como sugeriu Canguilhem ${ }^{23}$. Nessa direção e seguindo os passos do filósofo e médico francês, a saúde significaria estar doente e possuir a capacidade de se reestabelecer. No entanto, esse reestabelecimento dirigia-se para um ideal de "normalização" e reinserção no sistema social que parecem estar aquém da reconciliação com a sociedade "apesar da doença" (tomando-se como base a ideia de recovery).

Em acréscimo, registraram-se orientações representativas que contrariam lógicas reformistas, em certa medida, pois abarcavam um ideário que envolvia cura e reajustamento.

Sob outro aspecto, a possibilidade de convivência no meio comunitário apresentou-se como um valor ímpar. As atividades levadas a termo na comunidade foram reconhecidas como válidas e acolhidas pelos participantes.

Dessa forma, não se pode afirmar que os resultados tenham sugerido a desvalorização do cariz aberto e de base comunitária que reorientou as reformas relativas à assistência em Saúde Mental pós-pineliana em diversos países, incluindo Portugal. Deve-se recordar que a centralidade médicohospitalar como recurso privilegiado de assistência em Saúde Mental manteve-se constante ao longo das décadas de Reforma Psiquiátrica no país.

Esse fato se reflete na elaboração das racionalidades leigas, que, na investigação aqui descrita, em particular, identificaram a instituição hospitalar como um recurso imprescindível, ainda que não desejado. E também temido, de certo modo, por apresentar relações com as ideias de "queda" e de "fracasso".

Sob o ponto de vista histórico, relembre-se que o próprio Philippe Pinel, importante precursor da psiquiatria, entre o fim do século XVIII e início do século XIX, surge como um "reformista" e inspira movimentos por toda a Europa. A opção por desacorrentar os loucos no Hospital Bicêtre, em Paris, para a introdução do chamado tratamento moral, associa uma postura tolerante e humanista, que vem de encontro aos ideais iluministas da época e ao estudo racional e metódico do fenômeno da alienação mental ${ }^{24}$ (p. 114). Pinel passa a designar as pessoas acometidas por perturbações mentais como "doentes", para os quais o isolamento por meio da internação era considerado indispensável.

Movimentos de reforma posteriores, especialmente a partir da década de 1950, como a Psiquiatria Preventiva ou Comunitária, nos Estados Unidos; e Psiquiatria de Sector na França (inspiradora do movimento de Reforma Psiquiátrica em Portugal na década de 1960), não apresentavam como foco a extinção das instituições basilares, mas seu aperfeiçoamento por meio de reformulação interna como espaço de tratamento ${ }^{25}$. Essas raízes históricas não podem ser negligenciadas quando se trata de compreender as racionalidades leigas contemporâneas em Saúde Mental no país.

Em relação à Psiquiatria de Sector, a fim de se avançar em análises mais profícuas, deve-se observar seu caráter revolucionário, e não apenas restringi-la a abordagens clínicas ou ergonômicas. Uma das bases fundamentais da Psiquiatria de Sector voltava-se para a transformação nas relações em Saúde Mental25.

O próprio François Tosquelles, psiquiatra catalão e precursor do movimento, afirma que somente "na singularidade da experiência, na materialidade do percurso, algumas distâncias podem ser 
encurtadas" 26 (p. 89), referindo-se à necessidade de se perceber quais as reais demandas de um determinado momento, não com base em especialismos ou ideologias, mas na capacidade de estar com o outro, indispensável àqueles que pretendem enveredar pela seara da Saúde Mental. Assim, entende-se que estar com o outro significa reconhecer quais são as racionalidades que orientam suas ações e, desse modo, estar mais apto a acompanhá-lo.

A investigação empreendida sugere que a lógica comunitária apresenta-se permeada pela lógica manicomial, sem que isso signifique contradição. Trata-se de um arranjo complexo e plural que alia a disponibilidade dos serviços, respostas consideradas resolutivas e o desejo de preservação identitária.

Abordagens que permitem a aproximação com a complexidade e a singularidade, como as que envolvem as racionalidades leigas, favorecem o contato com múltiplas dimensões humanas e permitem visualizar o fenômeno do adoecimento como um processo integral, no qual saúde e doença não se opõem, conforme descrito por Marcel Mauss ${ }^{27}$ em seus percursos antropológicos.

\section{A governação da Saúde Mental em Portugal}

Em Portugal, o redirecionamento da filosofia hospitalar, no sentido da implementação de estruturas assistenciais de base comunitária, iniciou-se nos anos 1960 com a Lei de Saúde Mental no 2118, de 1963, inspirada na Psiquiatria de Sector Francesa. Mas, na prática, ela não foi implementada, ou melhor, a sua implementação ficou comprometida em vários períodos, apesar de sucessivamente legislada.

A Lei de Saúde Mental lançou os princípios reformadores da política de assistência psiquiátrica vigente - setorização dos serviços psiquiátricos e criação de Centros de Saúde Mental - com o objetivo de desospitalizar a psiquiatria e de levá-la às comunidades. A implementação dessa filosofia tem sofrido importantes desvios relacionados com a grave deficiência em matéria de criação de serviços de apoio à integração na comunidade.

No que respeita aos serviços comunitários, estes últimos trinta anos durante os quais a tendência para a não institucionalização de novos pacientes (suportada pela solidariedade primária da família e não pela efectiva implementação de uma política de base comunitária que exigia a criação de dinâmicas comunitárias que potenciassem a inserção social das pessoas com doença mental) teve lugar juntamente com a manutenção de doentes crónicos de evolução prolongada que permaneciam nos hospitais, os Governos não se preocuparam em criar serviços comunitários $^{28}$. (p. 3)

A organização de serviços para as pessoas com doença mental nunca foi encarada pela Segurança Social: enquanto doentes, "pertencem" à política da saúde. Só com a reforma da Lei de Saúde Mental de 1998 é que se irá colocar a exigência da atuação interministerial para enfrentamento das necessidades específicas da Saúde Mental.

A nova lei, publicada em 24 de julho de 1998 (Lei n. ${ }^{\circ}$ 36/98 - Lei de Saúde Mental) ${ }^{29}$, não constituiu uma ruptura com os princípios aceites anteriormente, embora tenha acentuado e oficializado a necessidade de criação de uma rede diversificada de respostas articuladas entre si que exigem colaboração interministerial e com as organizações sociais comunitárias.

Como apontou Alves ${ }^{1,19}$, no fim da década de 1990 e na primeira década dos anos 2000, os serviços públicos orientaram a sua atuação sobretudo para as consultas, internamento e também, embora com menos frequência, para as hospitalizações de dia. Os privados, além destes, utilizam de forma mais generalizada os métodos psicoterapêuticos (psicanálise, psicoterapia, terapia familiar, psicodrama, grupanálise, etc.) que, apesar de existirem nos hospitais públicos e apesar de, muitas vezes, a sua formação ser financiada por estes, não representam mais do que experiências pontuais. Em outras palavras, o sistema público não está organizado de forma que possa generalizar esse tipo de abordagem, dada a sua rigidez estrutural.

Mais recentemente, de acordo com a publicação anual do governo português "Saúde Mental em Números - 2015"30, cujo objetivo é acompanhar as ações desenvolvidas no Programa Nacional para 
a Saúde Mental (PNSM), da Direção-Geral da Saúde (DGS), os melhores resultados relacionados ao processo de transição em Saúde Mental, no qual a desinstitucionalização e o desenvolvimento de cuidados na comunidade são considerados fundamentais, foram encontrados nas percentagens de realização nas áreas do desenvolvimento dos serviços de ambulatório em hospitais gerais e nas percentagens que indicam o aumento do número de camas nos hospitais gerais. Em âmbito comunitário, foram registradas expansões nos serviços de ambulatório, no desenvolvimento de equipes e na criação de alternativas residenciais na comunidade, especialmente por meio das Instituições Particulares de Solidariedade Social (IPPS). Quanto às barreiras ao processo de transição em Saúde Mental, o documento aponta para a baixa prioridade política e o financiamento insuficiente ou inadequado.

Já o último "Relatório da Primavera do Observatório Português dos Sistemas de Saúde" 31 (OPSS, 2016) afirma que a Saúde Mental tem sido uma das áreas mais afetadas pela crise econômica nos últimos anos, destaca o subfinanciamento da área como um fator relevante e informa que em Portugal registra-se uma das mais elevadas prevalências de doença mental da Europa, com aumento das taxas de suicídio em idade ativa ( $<65$ anos). Segundo o relatório, embora uma percentagem significativa de pessoas com doenças mentais graves permaneça sem acesso a cuidados em Saúde Mental, as que têm acesso nem sempre se beneficiam de modelos de intervenção atualmente considerados essenciais, como programas de tratamento e de reabilitação psicossocial.

Concorda-se com Hespanha ${ }^{32}$ no que se refere à possibilidade de um novo falhanço em relação ao Plano de Acção 2007-2016³, sem que se tenham executado as ações e as mudanças necessárias em nível governamental.

No entanto, conforme o estudo das racionalidades leigas tem sugerido ao longo das últimas décadas, há que se destacar o modo como se concebem e se implementam serviços de saúde que as pessoas que convivem com transtornos mentais realmente queiram utilizar, aliado à criação de estratégias de proteção e de promoção da Saúde Mental da população de forma geral e não apenas no atendimento à crise ou a quadros psicopatológicos já instalados. Não se pode almejar que a expansão da rede de serviços comunitários por si transforme processos segregadores e excludentes enraizados nas representações sociais e na cultura.

O registro histórico de pouca participação de profissionais e de movimentos sociais organizados para a consolidação da reforma da Saúde Mental portuguesa deveria favorecer o olhar para as relações que se estabelecem concretamente e avançar a partir delas, não contra elas. A resistência, seja corporativa ou leiga, não pode ser superada pela imposição de normas reformistas, ainda que se tenha apreço por seus princípios e diretrizes.

Trata-se de um processo consideravelmente sensível às racionalidades leigas e que exige, portanto, diálogo, negociação e uma firme aposta na capacidade de participação e envolvimento das pessoas, do modo que for possível e que tais pessoas percebam como necessário. Processos de reforma que não se iniciem com abertura semelhante distinguem-se apenas em conteúdo de propostas consideradas antidemocráticas ou autoritárias.

A base dos movimentos em Saúde Mental que obtiveram êxito, seja na italiana e democrática Trieste ou no inovador âmbito clínico francês de La Borde ${ }^{24}$, foi um desejo de transformação que envolveu os coletivos e, por isso, pôde se expressar com vigor, não de modo homogêneo, mas certamente com coerência e direção.

Segundo Rosa, Alves e Silva ${ }^{34}$, a sociedade portuguesa apresenta-se estratificada e sob acentuado poder médico corporativo, o que torna ainda mais relevante o estudo das racionalidades leigas na qualidade de "saberes práticos construtores dos sentidos subjetivos de saúde" (p. 29).

Tal pressuposto não é algo desconhecido do campo sociológico, em especial na Sociologia da Saúde, conforme apontado recentemente por Carapinheiro e Correia ${ }^{13}$. A condição de sujeito e a preservação identitária são fatores decisivos nas questões que envolvem o acompanhamento em Saúde Mental, conforme já destacado anteriormente.

Em Portugal, apesar da existência de legislações sucessivas no campo da Saúde Mental, tais legislações não se traduziram na mesma medida em relação à implantação dos serviços e na execução de práticas alternativas. As raízes na Psiquiatria de Setor francesa mantêm laços estreitos com a 
centralidade hospitalar e com a própria Psiquiatria e seus profissionais. A divisão entre os âmbitos clínico/biomédico e psicossocial se revelam na rede de serviços: clínicos para as estruturas hospitalares e psicossociais para os serviços comunitários. Em função da necessidade participativa, as famílias apresentam potencial reivindicatório, porém, encontram-se sobrecarregadas.

Iniciativas como a "Carta para a Participação Pública em Saúde" 35 - lançada durante o segundo semestre de 2016 e resultante do projeto "MAIS PARTICIPAÇÃO, melhor saúde", organizada por signatários que envolvem organizações, associações diversas e individualidades portuguesas, incluindo o sociólogo Boaventura de Sousa Santos - parece refletir a busca por suprir, de algum modo, uma lacuna histórica no que se refere à construção coletiva e participativa nos sistemas de saúde oficiais.

No que tange à implantação de novos serviços, merece destaque o trabalho das associações no apoio à doença mental, ratificado pelos documentos oficiais do governo português anteriormente referidos ${ }^{30,31}$.

Nessa direção, convém registrar as investigações de Portugal e Nogueira ${ }^{36}$ que apontam para potencialidades e fragilidades de tais associações, como a proximidade e o atendimento individualizado, informação e combate ao estigma, diminuição das internações hospitalações e recidivas, capacidade de trabalhar em rede, aliadas a dificuldades financeiras e escassez de recursos humanos. As autoras informam que a expansão das associações a partir da década de 1990 não se deve à organização de familiares e usuários, mas a dispositivos externos, notadamente no âmbito legislativo, fato que remete ao distanciamento das racionalidades leigas na configuração das políticas de saúde mental no país.

\section{Considerações finais}

\section{Para abrir a Saúde Mental ao mundo da vida}

A necessidade de articulação comunitária não restrita à integração nas famílias se apresenta como o fator decisivo no âmbito da reabilitação psicossocial, sem que se desconsidere a expansão dos serviços, obviamente. As investigações mais recentes sugerem o fato de que epistemologias que atentem para o paradigma aberto e comunitário em Saúde Mental e as metodologias de intervenção resultantes podem ser tão ou mais influentes do que a mera expansão dos serviços, como a história já o demonstrou.

Isso significa conferir espaço à revisão dos diagnósticos e resgatar a direção nosológica em Saúde Mental, sem naturalizar o veredito psiquiátrico, algo incoerente com a proposta de acompanhamento e maior participação social das pessoas acometidas por transtornos mentais.

A percepção do panorama contemporâneo da Saúde Mental em Portugal poderia apontar para o facto de que intervenções efetivamente substitutivas nos serviços resultariam de organizações estruturais dos sistemas de saúde no país.

No entanto, um olhar micropolítico sugere que estruturas alternativas, no caso português, não se consolidarão (e tampouco ocorrerão) caso as bases epistemológicas sob as quais as intervenções estejam fundamentadas reflitam visões segregacionistas e institucionalizantes/transinstitucionalizantes de cuidados em Saúde Mental.

Tais visões despontam em parte como resultado das representações configuradas historicamente em relação à loucura. Contudo, não se trata apenas de inventar algo novo, mas de lidar com o que já se produziu e de como se produz cuidados em Saúde Mental cotidianamente.

Atravessa-se um momento histórico que poderá resultar em abordagens mais complexas no atendimento em Saúde Mental, principalmente em relação a quadros mais graves, para os quais a intervenção medicamentosa e a internação se apresentam como importantes referenciais nas representações de técnicos e utentes/usuários.

Contudo, não há medicação que substitua por si o acompanhamento longitudinal e tampouco internações que possibilitem o desenvolvimento das competências necessárias à vida cotidiana no território comunitário. A transformação e a recriação das ações em Saúde Mental requerem preparo 
formativo e vivencial e uma concepção ampliada de saúde que permita acolher diversidades de entendimento e de expressão do adoecimento mental.

Os desafios contemporâneos envolvem a potencialização de organizações substitutivas e o incentivo a novas bases epistemológicas para a formação profissional que incluam a elaboração de estratégias interventivas mais próximas das necessidades e dos universos simbólicos locais.

Ainda que esse fato pareça traduzir o óbvio, fenômenos ainda muito atuantes, como a transinstitucionalização ${ }^{37}$, ou seja, a mera transposição da institucionalização de um local para outro, apresentam-se como obstáculos a efetivas mudanças em Saúde Mental. Ações que não se voltem para a reinserção comunitária refletem uma insidiosa lógica manicomial que insiste em se manifestar sob o horizonte do medo e não em possibilidades de vida e de movimento, por vezes mais restritas; em outras, surpreendentes.

Com isso, pretende-se articular à esfera pragmática, fundamental na organização dos serviços de reabilitação psicossocial, posturas epistemológicas que estejam atentas e críticas aos seus próprios movimentos. Dirige-se contemporaneamente um chamado às ciências humanas e sociais para responder às questões emergenciais que se apresentam em realidades sociais permeadas por crises econômicas e políticas.

No entanto, avançar socialmente implica questionar o instituído a partir dos limites do que se sabe, como diria Deleuze ${ }^{38}$; ou então reconhecer o potencial criador que se apresenta na instituição imaginária da sociedade, como nos apontou o grego Cornelius Castoriadis ${ }^{39}$ ao descrever os movimentos indeterminados que permitem transformações sociais com base na recriação do instituído.

\section{Colaboradores}

As autoras participaram, igualmente, de todas as etapas de elaboração do artigo.

\section{Referências}

1. Alves F. A doença mental nem sempre é doença. Racionalidades leigas sobre saúde e doença mental - um estudo no norte de Portugal. Porto: Afrontamento; 2011.

2. Alves F. Racionalidades leigas sobre saúde e doença mental - um estudo no Norte de Portugal. In: Fontes BASM, Fonte EMM, organizadores. Desinstitucionalização, redes sociais e saúde mental: análise de experiências da reforma psiquiátrica em Angola, Brasil e Portugal. Recife: Editora Universitária UFPE; 2010. p. 25-69.

3. Alves F. Racionalidades leigas e produção local de saberes em saúde. In: Carapinheiro G, Correia T, organizadores. Novos temas de saúde, novas questões sociais. Lisboa: Mundos Sociais; 2015. p. 113-28.

4. Silva L, Alves F. Compreender as racionalidades leigas sobre saúde e doença. Physis. 2011; 21(4):1207-29.

5. Alves F, Caeiro S, Azeiteiro U. Lay rationalities of climate change. Int J Clim Chang Str Manage. 2014; 6(1):2-4.

6. Viegas V, Azeiteiro UM, Dias JA, Alves F. Alterações climáticas, percepções e racionalidades. $\mathrm{RGCl}$. 2014; 14(3):347-63. 
7. Dicionário de Latim-Português/Português-Latim. 11a ed. Porto: Porto Editora; 2014.

8. Dicionário Michaelis. 8a ed. São Paulo: Melhoramentos; 2011.

9. Webster's Revised Unabridged Dictionary [Internet] [citado 23 Set 2016]. Disponível em: http://www.dictionary.com/browse/laic.

10. Giddens A. Novas regras do método sociológico. Lisboa: Gradiva; 1996.

11. Silva LF. Saúde e doença no saber leigo. In: Alves F, coordenador. Saúde, medicina e sociedade: uma visão sociológica. Lisboa: Pactor; 2013. p. 174-8.

12. Santos BS. O Estado e a sociedade em Portugal (1974-1988). Porto: Edições Afrontamento; 1990.

13. Carapinheiro G, Correia T, organizadores. Novos temas de saúde, novas questões sociais. Lisboa: Mundos Sociais; 2015. Diálogos com a sociologia da saúde e da doença; p. 1-15.

14. Sanches SA, Swildens WE, van Busschbach JT, Stant AD, Feenstra TL, van Weeghel J. Cost effectiveness and budgetary impact of the Boston University approach to psychiatric rehabilitation for societal participation in people with severe mental illness: a randomised controlled trial protocol. BMC Psychiatry. 2015; 15:217. doi: 10.1186/s12888-015-0593-8.

15. Goffman E. Estigma - notas sobre a manipulação da identidade deteriorada. Rio de Janeiro: Livros Técnicos e Científicos; 1982.

16. Nicolau KW, Escalda PMF, Furlan PG. Residências terapêuticas como estratégias substitutivas: equacionando a necessidade de tutela e de autonomia para pessoas que convivem com transtornos mentais. In: Anais do $11^{\circ}$ Congresso Brasileiro de Saúde Coletiva; 2015; Goiânia. Goiânia; 2015 [citado 12 Mai 2017]. Disponível em: http://www.saudecoletiva.org.br/anais/index_int.php?id_ trabalho=2113\&ano=\&ev $=\#$ menuanais.

17. Foucault M. A arqueologia do saber. Lisboa: Edições 70; 2014.

18. Henderson J, Fuller J. 'Problematising' Australian policy representations in responses to the physical health of people with mental health disorders. Aust J Soc Issues. 2011; 46(2):183-203.

19. Alves F, coordenador. Saúde, medicina e sociedade: uma visão sociológica. Lisboa: Pactor; 2013. Lidar com a doença mental: os sistemas de cuidados e os itinerários terapêuticos. p. 219-36.

20. Alves F, Nicolau KW, Escalda PMF, Furlan PG. Visita técnica à associação nova aurora - reabilitação e reintegração psicossocial (ANARP) na cidade do Porto, Portugal. In: Gerhardt TE, Trad LAB, Barsaglini RA, organizadores. In: Anais do $7^{\circ}$ Congresso Brasileiro de Ciências Sociais e Humanas em Saúde; 2016; Cuiabá. Cuiabá; 2016. p. 444 [citado 12 Maio 2017]. Disponível em: https://www.abrasco.org.br/site/noticias/institucional/ disponiveis-os-anais-do-7ocbcshs/24766/.

21. Baccari IOP, Onocko-Campos RT, Stefanello S. Recovery: revisão sistemática de um conceito. Cienc Saude Colet. 2015; 20(1):125-36.

22. Teixeira CCV. Contributos para o desenvolvimento de serviços de reabilitação psicossocial/psiquiatria em Portugal: situação atual, barreiras e desafios [tese]. Coimbra: Faculdade de Psicologia e de Ciências da Educação, Universidade de Coimbra; 2013.

23. Canguilhem G. O normal e o patológico. 6a ed. São Paulo: Forense Universitária; 2009.

24. Pereira MEC. Pinel - a mania, o tratamento moral e os inícios da psiquiatria contemporânea. Rev Latinoam Psicopatol Fundam. 2004; 3:113-6. 
25. Passos ICF. Reforma psiquiátrica: as experiências francesa e italiana. Rio de Janeiro: Fiocruz; 2009.

26. Gallio G, Constantino M. François Tosquelles, a escola de liberdade. In: Lancetti A. SaúdeLoucura 4: grupos e coletivos. São Paulo: Hucitec; 1993. p. 85-128.

27. Mauss M. Sociologia e antropologia. São Paulo: Cosac Naify; 2008.

28. Alves F. A família como suporte da política de saúde mental em Portugal [dissertação]. Porto: ISSSP; 1998.

29. Lei de Saúde Mental (PT). Lei n. ${ }^{\circ}$ 36, de 24 de Julho de 1998. Estabelece os princípios gerais da política de saúde mental e regula o internamento compulsivo dos portadores de anomalia psíquica, designadamente das pessoas com doença mental. Diário da República, 14 Jul 1998 [citado 11 Fev 2016]. Disponível em: http://www.pgdlisboa.pt/leis/lei_ mostra_articulado.php?nid $=276 \&$ tabela $=$ leis\&so_miolo $=$

30. Portugal. Saúde Mental em Números - 2015. Lisboa: Direção-Geral da Saúde; 2016 [citado 02 Jun 2016]. Disponível em: https://www.dgs.pt/em-destaque/portugal-saudemental-em-numeros-201511.aspx

31. Observatório Português dos Sistemas de Saúde (OPSS). Relatório de primavera 2016: saúde procuram-se novos caminhos. Lisboa; 2016 [citado 01 Jul 2016]. Disponível em: http://www.opss.pt/sites/opss.pt/files/Relatorio_Primavera_2016_1.pdf.

32. Hespanha P. Caso 3: caso de Portugal - o processo errático da desinstitucionalização em Portugal. In: Fontes B, Fonte E, Hespanha P. Políticas de Saúde Mental em Angola, Brasil e Portugal: Desafios para o Século XXI. In: Alves F, coordenador. Saúde, medicina e sociedade: uma visão sociológica. Lisboa: Pactor; 2013. p. 123-35.

33. Ministério da Saúde (PT). Proposta de plano de acção para a reestruturação e desenvolvimento dos serviços de saúde mental em Portugal 2007-2016. Relatório da Comissão Nacional para a Reestruturação dos Serviços de Saúde Mental. Lisboa: MS; 2007

34. Rosa R, Alves F, Silva LF. Protagonismos alternativos em saúde: contexto teórico de uma pesquisa compreensiva. RECIIS. 2011; 5(4):24-31.

35. Carta para a Participação Pública em Saúde [Internet]. [citado 23 Set 2016]. Disponível em: http://peticaopublica.com/pview.aspx?pi=maisparticipacao

36. Portugal S, Nogueira C. Se não o hospital, então onde? Respostas societais para a desinstitucionalização da doença mental. In: Fontes BASM, Fonte EMM, organizadores. Desinstitucionalização, redes sociais e saúde mental: análise de experiências da reforma psiquiátrica em Angola, Brasil e Portugal. Recife: Editora Universitária da UFPE; 2010. p. 223-53.

37. Barroso SM, Silva MA. Reforma psiquiátrica brasileira: o caminho da desinstitucionalização pelo olhar da historiografia. Rev SPAGESP. 2011; 12(1):66-78.

38. Deleuze G. Lógica do sentido. 5a ed. São Paulo: Perspectiva; 2015.

39. Castoriadis C. A instituição imaginária da sociedade. 6a ed. São Paulo: Paz e Terra; 2007. 
Alves F, Nicolau KW. Racionalidades legas y gobernación de la Salud Mental en Portugal. Interface (Botucatu). 2017; 21(63):799-810.

El artículo reafirma la importancia de las racionalidades legas producidas en Salud Mental como expresiones válidas de saber, con especial atención para los aspectos éticos relacionados a los usos sociales de los conocimientos generados. Se defiende la idea de que deben servir para la creación de estrategias innovadoras que respondan efectivamente a las necesidades de las personas y como contra-poderes a las lógicas hegemónicas. El contexto de la gobernación de la Salud Mental en Portugal y las características estructurales de la sociedad portuguesa se reflejan en los servicios efectivamente implementados y en la percepción de los usuarios con relación a su condición. La valorización de las racionalidades legas en un escenario hegemónicamente tecnicista y biomédico posibilita reafirmar la diversidad como condición humana. En esa dirección, se insiere como fundamento para el abordaje en realidades complejas y plurales como la Salud Mental, incorporando la dimensión cultural a las acciones desarrolladas.

Palabras clave: Racionalidades legas. Salud mental portuguesa. Desinstitucionalización.

Submetido em 27/10/16. Aprovado em 26/01/17. 